\title{
Does Size Matter? The Implications of Firm Size on Enterprise Systems Success
}

\author{
Darshana Sedera \\ Queensland University of Technology \\ d.sedera@qut.edu.au
}

\begin{abstract}
With the increasing emphasis on globalization and consumer demands in highly competitive markets, organizations have attempted to integrate and standardize across their corporate subsidiaries by implementing Enterprise Systems (ES). In such corporate-wide ES implementations, system requirements are dictated by headquarters, favouring large subsidiaries, and thus potentially compromising the unique business requirements of smaller units. This research reports findings from an ES initiative within a group of large, medium, and small organizations, where the impact of organization size is assessed in relation to the level of system success and knowledge-management competence. The results of this analysis suggest that (i) large organizations, in contrast to their smaller counterparts, receive greater benefits in terms of both Individual and Organizational Impacts, (ii) while no such differences were observed in relation to System and Information Quality. Similarly, (iii) no differences were observed in relation to knowledge-creation competencies amongst large, medium, and small organizations. However, (iv) differences were observed between the large and smaller firms on their Knowledge-Retention and Knowledge-Transfer competencies.
\end{abstract}

Keywords: Enterprise System; Organization Size; Knowledge Management; Cluster Analysis; Multi-group Analysis

\section{Introduction}

With the increasing emphasis on globalization and highly competitive markets, corporations are looking to Enterprise Systems (ES) as a way of integrating and standardizing across all their corporate subsidiaries (Laukkanen, Sarpola, \& Hallikainen, 2007; Sedera, Lokuge, Grover, Sarker, Sarker 2016). Such corporate-wide ES implementations are widespread in multi-national companies, and the presence of such ES implementations is growing in publicsector organizations. These ES initiatives are motivated by the desire to create integrated, standardized, and efficient processes, providing predictable outputs across all subsidiaries (Avison \& Malaurent, 2007). In order to reach this management control "dream," companies promote organizational discipline both by requiring ES users to follow prescribed corporate processes and by limiting their access to specific organizational roles. The substantial growth of these centralized ES implementations in large corporations in the past two decades - more than 30,000 companies worldwide, according to Mabert et al. (2003) - is a major testament to this quest for standardization, visibility, and control.

In multidivisional corporations, Enterprise Systems are deployed across different geographical, cultural, or organizational boundaries, using what are commonly known as "global templates." Global templates in these ES implementations typically omit specific requirements that may vary substantially from one subsidiary to the next, depending on the local standards, rules, norms, and values attaining simplicity and standardization of operational procedures across all organizational entities. Global templates tend to favour the standards, structures, goals, and objectives of the parent company or its dominant subsidiaries. As a consequence, when companies fail to account for the specific needs of all their subsidiaries, these neglected subsidiaries are less likely to succeed in the long term (Avison \& Malaurent, 2007). In relation to the ownership costs of full-scale Enterprise Systems, large companies and their large subsidiaries, due to their economies of scale, are more able to cover these costs, whereas small and medium enterprises (SMEs) struggle with finding a balance 
between these costs and smaller (Salim, Sedera, Sawang, Alarifi, Atapattu, 2015), easier-to-use systems that may be more suited to their needs (Wang \& Hamerman, 2008).

Information systems researchers generally agree that, for the purposes of their research, there are three firm sizes: small, medium, and large. However, as Goode and Gregor (2009) point out that IS research lacks a coherent argument on how firms should be grouped based on 'size'. Past IS research has employed a myriad of features and heuristics to categorize organizations according to organization size.

Having studied nearly 2000 research papers over 11years, Goode and Gregor (2009) identified 21 constructs underpinning the size construct and 25 heuristics of measuring firm size - with no clear definition or relationship among these measurement constructs. They observed that the most often employed criteria for determining organizational size - the number of employees - is fraught with inconsistencies when determining what is a small, medium, or a large organization1. This diversity of benchmarks has made it almost impossible to derive observations beyond a particular region or country. They also identified the number of the IT staff and the size of the IT budget as two criteria that closely align with IS studies, but found similar inconsistencies to the number-of-employees metric. Also, it is often difficult to obtain sensitive budget details in many circumstances. In conclusion, Goode and Gregor (2009) encouraged IS researchers to develop IS-specific criteria to group organizations according to "firm size." Reflecting this charge, a secondary motive of this study is the derivation of a repeatable IS-specific size classification (described in the data analysis section).

This profusion of arguments and diversity of results notwithstanding, all past IS researchers agree that large, medium, and small organizations select, implement, use, and manage information systems differently. Appendix A extends the discussion of Goode and Gregor (2009) and summarizes prior studies on firm size in relation to (i) system selection and implementation, and (ii) post-implementation management and outlines the differences between small, medium, and large organizations. The highlighted cells in Appendix A show those characteristics that are considered favourable for ES implementation and postimplementation success. These summarized characteristics suggest that large organizations have advantages in terms of financial resources, knowledge, and ability to make investments throughout the system lifecycle; and a tolerance of losses, are well-structured, have a sophistication in IT, and they follow a formal IS acquisition procedure. Prior research concludes that such conditions are favourable to Enterprise System success. Small organizations, on the other hand, have other advantages, including the ease of managing change and experiencing less complexity, which contribute to high levels of ES success.

The primary objective of this study is to understand whether all organizations, regardless of their size, are capable of deriving similar benefits from corporate-mandated Enterprise System initiatives. Our study specifically observes (i) the level of Enterprise System success (ESsuccess) throughout the lifecycle of the implementation and subsequent use at the onwards/ upwards phase of the ES (Markus, Axline, Petrie, \& Tanis, 2003) and (ii) the organization's competency in managing knowledge-management initiatives (KM-competence) throughout the ES lifecycle. The inclusion of KM-competence - a widely cited critical success factor for ES-success (Sedera \& Gable, 2010) - enables us to study the extent to which different sized organizations are capable of managing the entire ES lifecycle, not just the initial implementation phase.

\footnotetext{
${ }^{1}$ For example, while the Blemish companies with less than 90 employees are classified as small, in the U.S., a "small" company must have less than 100 employees. According to European Union guidelines, companies with less than 50 employees are classified as small, and companies with less than 500 are considered mid-sized. However, within the same Euro-zone, Germany defines a small organization as one with less than 250 employees. In the Enterprise System context, SAP positions its scaled-down ES Business One ${ }^{\circledR}$ application especially for "small" organizations, which they define as less than 100 employees.
} 
Research on corporate-wide ES implementations is of interest to both researchers and practitioners, especially at a time when there is strong growth of multinational companies in high-growth economies like Brazil, Russia, India, and China (the "BRIC" countries). For instance, our findings should benefit researchers and practitioners interested in observing mergers and acquisitions that are increasingly common in the global economy. Organizationwide ES initiatives are also of interest to public-sector organizations. They too, like the organizations in this study, engage in large-scale ES initiatives in hopes of achieving efficiency gains across government departments. Our analysis of the ES literature for the period from 1995 to 2011 in the nine leading IS research publication outlets (eight leading IS journals ${ }^{2}$ and the ICIS Proceedings) did not yield any study on multidivisional, corporate-wide ES installations. The dearth of research in this important area can perhaps be attributed to the difficulties in gaining access to all the subsidiaries involved in a multidivisional ES initiative. Moreover, the effect of firm size on ES-success is seldom studied, with most ES studies concentrating on a single organization.

The current study findings are derived from a large multidivisional SAP initiative completed in the late 1990s, in which a group of large, medium, and small Australian state government departments were brought together under a single SAP installation. In this study, the characteristics of a corporate-wideESinitiative are narrated using the phenomena of "panoptic gaze" of Bentham (1971), cited in Semple (1993), and its information system extensions by Zuboff (1988). Our research model is derived from Sedera and Gable (2010), who observed a significant positive relationship between KM-competence and ES-success. The Sedera and Gable model in the current study is tested with firm size as a moderating variable. The homogeneous context - where all organizational units implemented the same ES at the same time, where all organizations were tracked throughout the entire ES lifecycle, and where all organizational units were part of the same parent organization - minimized the possible influence of extraneous variables.

\section{Global Templates in Enterprise Systems}

In this study, we conceptualize the centralized ES implementation through the use of "global templates" using the notions of the "panoptic gaze" (Bentham 1791; cited in Semple (1993)) and of the "information panopticon" (Zuboff, 1988). The panopticon concept, originally based on the work of Bentham (1791), refers to a prison architecture that employs a central tower for the observation of the prisoners. The central tower allows the guards to observe, opticon, all, pan, the prisoners without their being able to tell whether they are being watched. The panoptic gaze is a continuous surveillance that is hierarchical; the observers can observe the prisoners and can themselves be observed by their superiors; and one-way, the prisoners cannot see the observer, cannot see each other, and cannot know whether they are being observed $^{3}$. By applying the panopticon concept to IT, Zuboff (1988) proposed the term "information panopticon" to describe how computer technology makes work more visible to managers.

Sia et al. (2002) suggested that the information panopticon lens might produce a better understanding of the impact of ES use in organizations, where ES users are constantly being monitored by the tracking mechanisms embedded in the system. They argued that the transparency of the ES allows management to monitor the activities and decisions of their subordinates. Later, Elmes et al. (2005) pointed out that an ES provides greater control and enhanced management oversight of departments and subsidiaries. Thus, Enterprise Systems, in many ways, inherently supports bureaucratic control and enforces organizational discipline by requiring organizations and their employees to follow prescribed processes with access to

\footnotetext{
2 European Journal of Information Systems, Information Systems Journal, Information Systems Research, J ournal of Information Technology, J ournal of Management Information Systems, J ournal of Strategic Information Systems, J ournal of the Association for Information Systems, and MIS Quarterly. ${ }^{3}$ Zuboff (1988) provides the closed-circuit television camera surveillance in public spaces as an example of how technology brings a panoptic gaze into the daily lives of citizens.
} 
transactions restricted to their particular roles and responsibilities. Elmes et al. further suggest that Enterprise Systems, in comparison to earlier technologies, reflect the view of panopticon control through the integrated database that captures real-time information for monitoring and tracking user actions.

Global templates in ES initiatives help organizations achieve these objectives. Such templates purposefully omit any specific local organizational requirements (Elmes et al., 2005; Sia et al., 2002). Given the objectives of adopting a single ES for an entire organization - replacing disparate local legacy systems, integrating multiple business processes, standardizing business process and reporting requirements, standardizing data inputs and outputs, storing data in a common database, and ensuring information accessibility on a real-time basis across organizational boundaries (Laukkanen et al., 2007) - corporate headquarters or the lead organization demands minimal local customization at the subsidiary level (Avison \& Malaurent, 2007). The extent to which thelead organization manages to achieve a single global template with no or little customization at the subsidiary level increases its management control. In our study, the phenomenon of management control attained through global templates administered by a lead organization is examined using the concepts in information panopticon.

\section{The Study Context}

This study gathers data from a large-scale Enterprise System initiative at a group of Australian state government departments that implemented SAP as a corporate-wide Information System solution in the late 1990s. The ES initiative brought twenty-seven (27) state government departments under a single SAP implementation. The Treasury Department, one of the largest departments in the state, championed the initiative and played the central role of the "watch tower," providing overall management, from initial user requirements analysis (URA), to implementation, to continuing management of the system. This ES initiative is reported to be the first corporate-wide, public-sector SAP initiative in the world. It is also the first time an Australian state government has implemented a common management software platform statewide. The key events of the initiative are described below, in order to provide the study context and to demonstrate the role and influence that the Treasury Department played as the lead organization in this organization-wide ES initiative.

In 1993, the state Treasury department conducted a User Requirements Analysis (URA) that revealed substantial differences among the individual systems within each department. The URA also identified the need for a statewide system to provide better decision-making; streamlined workflow automation; and integrated asset management, statewide project costing, sales and distribution, and procurement.

Then in 1994, the Treasury Department sent Requests for Information (RFI) to key ES vendors with two mandatory requirements for all RFI submissions: (1) the ability to quickly and easily adapt to changes in organizational structures and business environments, through restructuring business units by merging or eliminating complete departments; and (2) the ability to standardize both cash and accrual accounting across all 27 departments. In October 1994, Requests for Offers (RFO) were sought from three short-listed ES vendors; and the Treasury Department selected SAP R/ 3 as their statewide Enterprise System in December 1994.

At the commencement of the implementation process, the Treasury Department stated seven specific strategic requirements for the ES initiative. These requirements were communicated to the implementation partner (a consulting firm), the software vendor, and to all state departments. The requirements of the ES initiative were as follows: (1) rationalize the legacy management systems with standardized enterprise software; (2) support statewide financial management through consolidation, integration, and standardization; (3) re-engineer business processes and encourage best practice resource management; (4) improve the quality of data for management purposes; (5) meet emerging whole-of-government needs; (6) achieve economies of scalein operations; and (7) enhance data collection and planning through system 
integration. The SAP implementation was to be completed at all of the installations by the end of 1995. As pointed out by Madapusi et al. (2005), implementation of such strategies require high levels of control, which in this case were provided by the state Treasury Department, employing global templates to control the entire implementation process from URA, RFI, to RFO processes, and the final selection of the system.

The ES implementations were structured around five centralized functional "hubs," with strategic decision-making centralized to the Treasury Department. These five hubs were created within and managed by the five largest departments within the state government, with some limited freedom to deviate from the global ES templates, based on the needs, strategies, products, and common services within each of the hubs. However, any changes to the global templates at the hub level were strongly influenced by the Treasury Department. This demonstrates the influence of large organizations on global templates, similar to that reported in prior research (Clemmons \& Simon, 2001; Madapusi \& D'Souza, 2005; Madapusi \& D’Souza, 2007; Zuboff, 1988).

In 1998, despite the anticipated benefits, one relatively small-sized department that provided corporate IT services to a group of other small agencies expressed its dissatisfaction with the SAP Enterprise System. It argued that, despite its rich functionality, SAP was too complex and costly to maintain and too rigid to make the modifications needed to suit the unique needs of the departments it was serving. After nearly three years of attempting to use the SAP ES, this small department was approved by the Treasury department to replace their SAP ES with a locally-produced FinanceOne Enterprise System that is specifically designed for SMEs. Figure 1 depicts the key historical events of the organization-wide ES implementation.

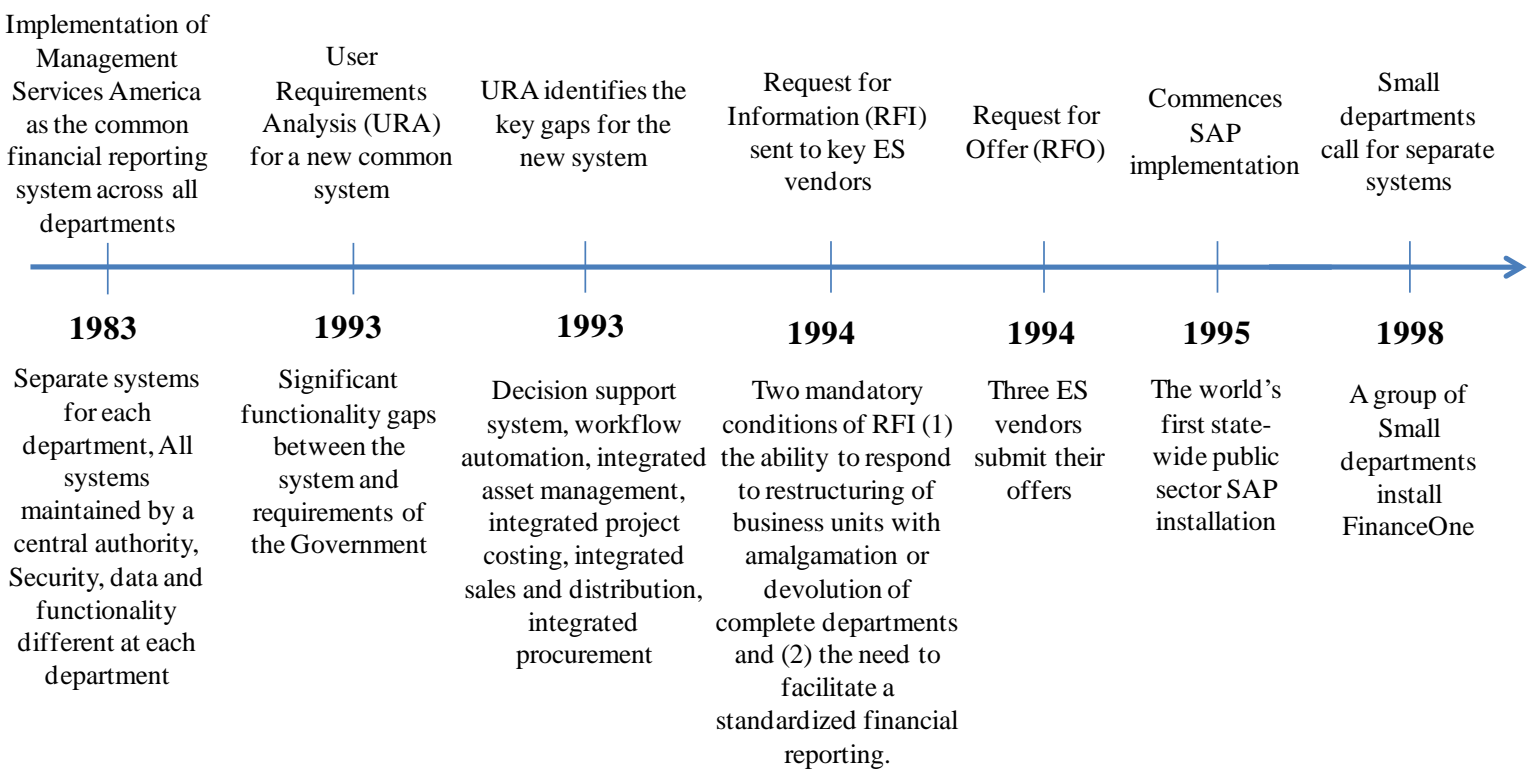

Figure 1: The history of key events and characteristics in the state government ES implementation

\section{Study Model, Instrument, and Data Collection}

The study model (Figure 2), shows the two key constructs and their relationship. It also highlights the moderating effect of firm size on both key constructs and their relationship. The model observes a firm-size effect on the outcome, ES-success, a key antecedent of ES-success (KM-competence) and the relationship between the constructs.

This depiction of the study model allows us to investigate three key hypotheses: (H1) large organizations receive higher levels of ES-success than their smaller counterparts in a organization-wide Enterprise System initiative; (H2) large organizations are more competent in $\mathrm{KM}$ than their smaller counterparts in a organization-wide Enterprise System 
initiative; and (H3) large organizations experience a stronger, more significant relationship between KM-competence and the level of success of the Enterprise System.

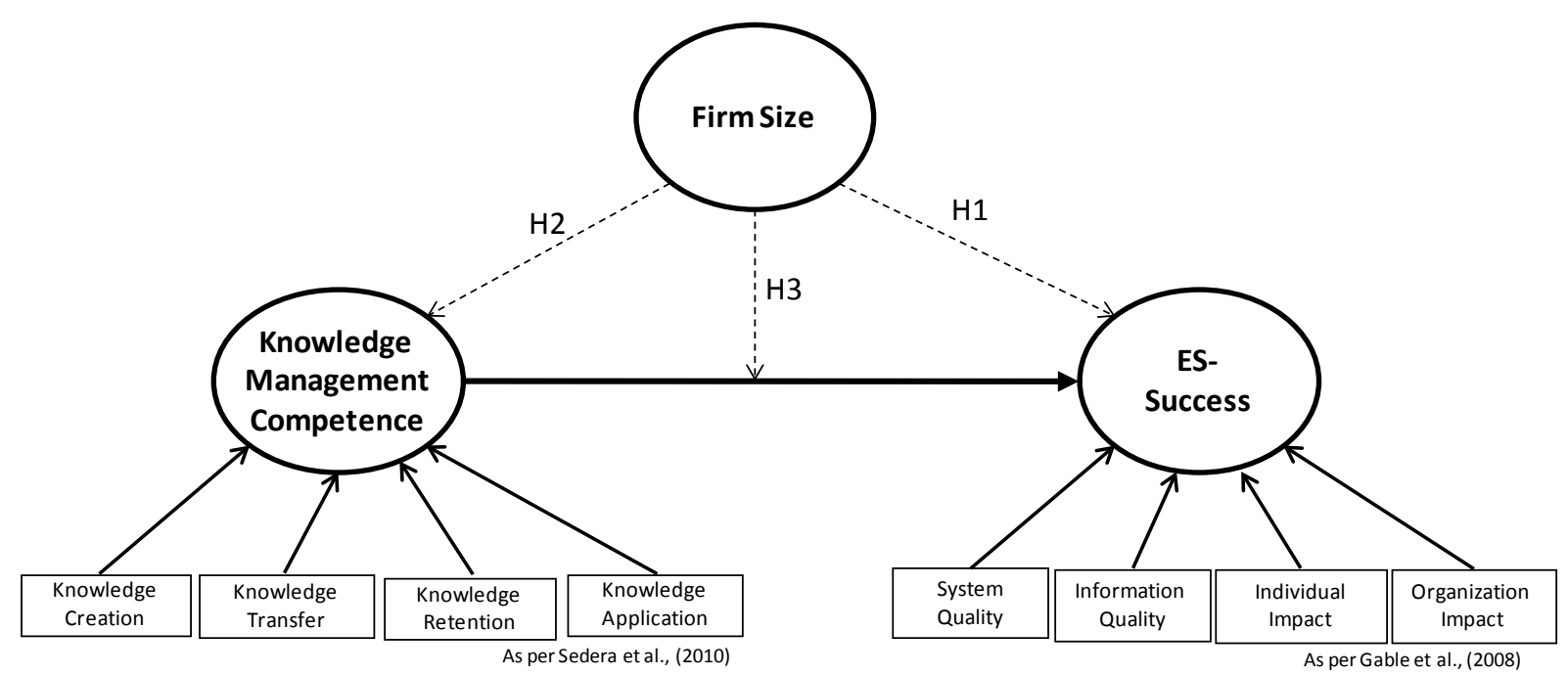

Figure 2: The Study Model

The dependent variable - ES-success - is conceptualized using the constructs of the IS Success Model of DeLone and McLean (1992), as modified by Gable Sedera and Chan. (Gable, Sedera, \& Chan, 2008). It is a formative, multidimensional index comprised of the four dimensions: two quantity dimensions, Systems Quality and Information Quality, and two impact dimensions, Individual Impact and Organizational Impact. In the Gable et al. study (2008), they found evidence of the necessity, additivity, and completeness of these four dimensions, measured using 27validated items to measure ES-success (IS-impact). The Gable et al. (2008) IS-Impact evaluation approach suggests that the two quality dimensions are measured at one point in time and the impact dimensions are measured retrospectively at the same point in time at which the quality is assessed. In combination, impact and quality measures represent a complete measure of the Information System success (its benefits).

The antecedent of ES-success - KM-competence - is measured using the work of Sedera and Gable. (2010). They define KM-competence using the four main phases of knowledge management, i.e., creation, transfer, retention, and application, that are distinct yet interrelated with competence in each phase, contributing to overall KM-competence in an organization (see Sverlinger, (2000) for a detailed summary of these knowledge-management phases). The knowledge creation phase corresponds primarily with the planning and implementation stages of the ES lifecycle. While it is recognized that knowledge creation continues to occur beyond the ES implementation stage, during implementation (and during major upgrades) there is an identifiable peak in new knowledge requirements and related knowledge creation. Typically, the necessary expertise is brought to bear by three key players contributing to the ES implementation and ongoing support: (1) the client organization, (2) the ES software vendor, and (3) the implementation partner (Gable, Heever, Erlank, \& Scott, 1997; Soh, Sia, \& Tay-Yap, 2000). According to Pan, Newell et al. (2007), knowledge transfer channels can be informal or formal, where unscheduled meetings, informal gatherings, and coffee-break conversations are examples of the informal transfer of knowledge. Although informal knowledge transfer promotes socialization and can be effective in small organizations, it precludes widespread dissemination (Alavi \&Leidner, 2001) - thus the focus of this study. Knowledge retention involves "embedding knowledge in a repository so that it exhibits some persistence over time" (Argote, McEvily, \& Reagans, 2003, p.572). Once the knowledge is created, transferred and retained, knowledge application occurs, where individuals apply the knowledge they have learned when interacting with the ES. Markus 
(2001) suggests that the source of competitive advantage resides, not in the knowledge itself, but in the application of the knowledge.

In summary, we argue that knowledge, created mainly during implementation, is subsequently, during post-implementation, transferred and then retained by the organization, and finally applied throughout the ES lifecycle (Pan \& Chen, 2005). Since each phase of knowledge management makes a unique contribution to KM-competence, the constructs are conceived of as dimensions "forming" KM-competence as a hierarchical, multidimensional, and formative index. Thus, the moderation effect of firm size on individual constructs and the relationship between the constructs, in addition to its moderating effect on the relationship, is appropriate, given that both ES-success and KM-competence are conceived as formative indexes.

Following the guidelines suggested by Cenfetelli and Bassellier (2009), Petter et al. (2007), and Diamantopoulos (2009), both constructs are conceived of as formative. Thus, the 27 measures of ES-success and the 10 measures of KM-competence: (i) need not co-vary, (ii) are not interchangeable, (iii) cause the core-construct, as opposed to being caused by it (arrows point in), and (iv) may have different antecedents and consequences in potentially quite different nomological nets. In addition to the 37 measures of the two constructs, five criterion items were obtained through the referent studies. One criterion item is aimed at gauging overall KM-competence, and the remaining four criteria measure the overall impact of ESsuccess.

All survey items were measured on a seven-point Likert scale with the end values "Strongly Disagree" (1) and "Strongly Agree," (7) and the middle value "Neutral" (4). The survey instrument also gathered detailed demographic data from the respondents regarding their job titles and descriptions of their daily involvement with the SAP system. Furthermore, objective information on each of the departments' number of SAP user licenses, hardware and software configurations of the SAP systems, and other major systems in place was gathered from Treasury Department documents. Simultaneous data collection from all 27 departments posed significant challenges. In order to ensure a high response rate and adequate representation of all departments, we sought endorsements from the highest officials in the Treasury Department ${ }^{4}$. The final survey instrument was then sent to 20 users for feedback on the question layout, clarity, and to determine the completion time. This process led to minor cosmetic changes to the format of the instrument. A respondent sample of 1200 active users was selected to participate in the study, with representation from all departments. The survey yielded a total of 319 responses. Nine responses were removed from the data analysis due to incomplete data or perceived frivolity, leaving 310 valid records for data analysis (a response rate of $27 \%)$.

\section{Data Analysis}

Having collected data from all 27 organizations, the next step was to classify these organizations into the three groups (i.e., small, medium, large) employing appropriate determinates of firm size. Our objective here was to develop a size-based criterion that we could use to group organizations. Such criterion should be specific to Information Systems, yet generalizable beyond the context of the current study.

We commenced our data analyses with cluster analysis aimed at exploring a natural scheme of grouping of organizations. Once the classification method was established, the respondents were then assigned to one of the three sizes. Next, we demonstrated descriptive and comparative statistics to compare the levels of ES success (H1) and KM-competence (H2) across large, medium, and small departments. Hypothesis H3 was tested with a comparative partial least squares (PLS) analysis of the three firm sizes using the multi-group analysis

\footnotetext{
${ }^{4}$ The study received formal approval through the signing of a Memorandum of Understanding outlining responsibilities of both the university and the state government departments, ethics of research, confidentiality, and intellectual property of study findings.
} 
techniques of Plouffe et al. (2001). This enabled us to understand the moderating impact of firm size on the relationship between KM-competence and ES-success (H3).

\subsection{Cluster Analysis: Exploring Firm Size}

Exploratory cluster analysis has the ability to identify "natural" classifications and to derive "common traits" of the respondents in an inductive manner (Punj \& Stewart, 1983). Specifically, we employed the two-step cluster procedure that has the ability to reveal natural groupings (or clusters) within a dataset that would otherwise not be apparent, with the loglikelihood as the distance measure (Bacher, Wenzig, \&Vogler, 2010). Reflecting prior studies, and that "three" may not be the "natural" number of firm sizes, we decided not to include apriori number of clusters and leave the analysis to determine number of clusters automatically. The cluster results of the criterion item that evaluates the overall impact of the system on the organization (Overall...the impact of SAP on the organization has been positive.) did, however, revealed three natural clusters with SPSS indicating 'good' for cluster quality (Bacher et al., 2010). This finding naturally follows the overall hypothesis of the study, that large organizations receive higher levels of ES-success than their smaller counterparts in a corporate-wide Enterprise System initiative. Our argument is that, to the extent that respondents observe similarities in perceived benefits, their responses will then yield "clusters" based on firm size. Having yielded three natural clusters categorizing every respondent, we then investigated possible explanations for these three clusters. Not being sure of the reasons for the three classes (apart from knowing that they originated from the criterion item), and also to confirm that these three groups are not arbitrary and/or the result of a random outcome, we explored logical explanations using contextual information provided to us by the Treasury Department.

The results of this analysis led to the identification of a direct relationship between the number of SAP user licenses and the three clusters. It revealed that all respondents in cluster 1 represented organizations with more than 1000 SAP user licenses, all respondents in cluster 2 represented organizations with 200-999 SAP user licenses, and 98\% of the respondents in cluster 3 represented organizations with less than 200 SAP user licenses (except one respondent, whose data were later moved to cluster 3). Interestingly, a focus group with the senior management at the Treasury Department designed to help with data interpretation revealed that they (the Treasury Department) too employ the same cut-offs as above in their internal management processes. The cut-off values for each group, based on the number of user licenses seem reasonable, with organizations with more than 1000 user licenses considered as large, less than 199 user licenses considered as small, and organizations with between 200-999 licenses considered as medium-sized. The respondent groups resulted through cluster analysis is depicted in Table 1.

\begin{tabular}{|c|c|c|c|c|}
\hline Cluster & Size & \# Respondents & \# Organizations & \# Licenses \\
\hline 1 & Large & 66 & 5 & $>1000$ \\
\hline 2 & Medium & 196 & 16 & $200-999$ \\
\hline 3 & Small & 48 & 6 & $<199$ \\
\hline Total & & 310 & 27 & \\
\hline
\end{tabular}

Table 1: The cluster analysis results corresponding to SAP user licenses

The current classification has several advantages. Unlike other commonly employed size classifications (e.g., number of employees, budget size, annual revenue, or profits), our classification and its cut-off points are more relevant to contemporary information systems. Secondly, the cut-off points are universal and can be used in any type of business, industry type, or geographic location to determine firm size of ES using organizations. Furthermore, information on user licenses is less intrusive and sensitive to the organization and can be obtained from multiple sources (client organizations, consultants, or from software vendors). 


\subsection{Construct Validity}

As depicted in the study model in Figure2, both constructs are specified as formative. Although constructs validation is not a focus of this study, it is important that the validity of the two constructs be established before making descriptive and comparative observations. We employ the validation techniques suggested in recent studies of Cenfetelli and Bassellier (2009), Diamantopoulos (2009), and Petter et al. (2007). For both ES-success and KM-competence constructs, first the variance inflation factors (VIF) were computed for each measure to assess the existence of multicollinearity between the formative measures. All measures (10 items in KM-competence and 27 in ES-success) were below the common VIF threshold of 10.0 as recommended by Kleinbaum et al. (1998).

We next identified both constructs through measurement relations (Hauser \& Goldberger, 1971; J oreskog \& Goldberger, 1975) following the prescriptions of Jarvis et al. (2003, p.214, Figure 5, Panel 3). The related validity test employs a Multiple Indicator Multiple Causes (MIMIC) model, using appropriate criterion measures as a reflective indicators, separately for each construct (Diamantopoulos \& Winklhofer, 2001).

The initial estimation of the MIMIC model for KM-competence revealed a reasonably good fit, with chi-square $=321$, d.f. $=20, \mathrm{RMSEA}=0.28, \mathrm{GFI}=0.88$, NNFI $=0.79$, and $\mathrm{CFI}=0.89$, and all items having significant t-values. Next, evaluating the absolute fit indicators of KMcompetence, the observed standardized RMR value of 0.077 represents a good fit. The MIMIC model of ES-success was developed using the four separate criterion measures as reflective indicators of each of the four ES-success dimensions. The statistics for the MIMIC model using the 27 items evidence good fit with the data (chi-square $=459.12$, d.f. $=129$, RMSEA $=0.014$, $\mathrm{GFI}=.89, \mathrm{NNFI}=0.87, \mathrm{CFI}=0.98, \mathrm{RMR}=0.10, \mathrm{SRMR}=.088, \mathrm{NFI}=0.97, \mathrm{NNFI}=0.87, \mathrm{IFI}$ $=0.98$, and $\mathrm{CFI}=0.98$ ).

\subsection{ES-Success: Descriptive and Comparative Statistics}

Table 2 presents the descriptive statistics of the three firm sizes in relation to the four ESsuccess dimensions. Large firms have received higher mean scores than their smaller counterparts for all four ES-success dimensions. Interestingly, the mean scores of small organisations are relatively higher than those of medium-sized organizations for all four success dimensions.

\begin{tabular}{|l|c|c|c|c|c|c|c|c|c|c|c|c|}
\cline { 2 - 14 } \multicolumn{1}{c|}{} & \multicolumn{9}{c|}{ Small } & \multicolumn{4}{c|}{ Medium } & \multicolumn{4}{c|}{ Large } \\
\cline { 2 - 14 } \multicolumn{1}{c|}{} & Mean & $\begin{array}{c}\text { St } \\
\text { Dev }\end{array}$ & $\begin{array}{c}\text { Skew- } \\
\text { ness }\end{array}$ & Kurtosis & Mean & $\begin{array}{c}\text { St } \\
\text { Dev }\end{array}$ & $\begin{array}{c}\text { Skew- } \\
\text { ness }\end{array}$ & Kurtosis & Mean & $\begin{array}{c}\text { St } \\
\text { Dev }\end{array}$ & $\begin{array}{c}\text { Skew- } \\
\text { ness }\end{array}$ & Kurtosis \\
\hline $\begin{array}{l}\text { Information } \\
\text { Quality }\end{array}$ & 4.02 & 1.46 & -0.07 & -0.60 & 3.90 & 1.31 & -0.23 & -0.90 & 4.17 & 1.34 & -0.37 & -0.27 \\
\hline $\begin{array}{l}\text { System } \\
\text { Quality }\end{array}$ & 4.03 & 1.20 & -0.41 & -0.75 & 3.77 & 1.19 & -0.21 & -0.60 & 4.12 & 1.08 & -0.42 & 0.42 \\
\hline $\begin{array}{l}\text { Individual } \\
\text { Impact }\end{array}$ & 4.52 & 1.45 & -0.59 & 0.00 & 4.47 & 1.46 & -0.60 & -0.50 & 5.10 & 1.14 & -0.30 & 0.30 \\
\hline $\begin{array}{l}\text { Organisational } \\
\text { Impact }\end{array}$ & 3.94 & 1.28 & -0.69 & 0.21 & 3.91 & 1.17 & -0.33 & -0.45 & 4.29 & 0.95 & -0.21 & 1.13 \\
\hline
\end{tabular}

Table 2: ES-success descriptive statistics

Table 3 reports the results of paired comparisons of the four success dimensions for the three firm sizes using independent sample t-tests (with results significant at 0.05 levels). The t-test results reveal significant differences between large organizations and SMEs in relation to the two impact dimensions: Individual Impact and Organizational Impact. Yet, the t-test results did not observe any differences among the three firm sizes for System Quality and Information Quality. 


\begin{tabular}{|c|c|c|c|c|}
\hline & \multicolumn{2}{|c|}{ Quality } & \multicolumn{2}{|c|}{ Impacts } \\
\hline & Information & System & Individual & Organization \\
\hline & Sig / df / t-value* & Sig/ df / t-value* & Sig/ df / t-value* & Sig/ df / t-value* \\
\hline Small & \multirow{2}{*}{$0.59 / 242 / 0.53$} & \multirow{2}{*}{$0.18 / 242 / 1.31$} & \multirow{2}{*}{$0.85 / 242 / 0.19$} & \multirow{2}{*}{$0.87 / 242 / .164$} \\
\hline Medium & & & & \\
\hline Small & \multirow{2}{*}{$0.56 / 112 /-.58$} & \multirow{2}{*}{$0.66 / 112 /-.44$} & \multirow{2}{*}{$0.01 / 112 /-2.41$} & \multirow{2}{*}{$0.05 / 112 /-1.89$} \\
\hline Large & & & & \\
\hline Large & \multirow{2}{*}{$0.15 / 260 /-1.43$} & \multirow{2}{*}{$0.30 / 260 /-2.09$} & \multirow{2}{*}{$0.00 / 142 /-3.59$} & \multirow{2}{*}{$0.00 / 136 /-2.36$} \\
\hline Medium & & & & \\
\hline
\end{tabular}

Table 3: Results of the independent sample t-test of ES-success (*Significant at 0.005 level)

The following observations are made for the ES-success dimensions through findings reported in Tables 2 and 3.

- $\quad$ Small and Medium organizations (SMEs) do not demonstrate significant differences in relation to the four success dimensions.

- $\quad$ Large and SMEs do not demonstrate differences for System Quality and Information Quality

- $\quad$ Large and SMEs demonstrate significant substantial differences in relation to Individual Impact and Organization Impact.

\subsection{KM-Competence: Descriptive and Comparative Statistics}

Table 4 presents the descriptive statistics of the three firm sizes for the four phases of KMcompetence. For knowledge creation during ES implementation, our results show similar mean scores for all three firm sizes. However, the mean scores of the two post-implementation knowledge-management competencies (i.e., knowledge transfer and knowledge retention) descend with the decreasing firm size. Theknowledge application dimension assesses whether similar patterns were observed in relation to the post-implementation phase of KMcompetence, with large organizations receiving the highest mean score.

\begin{tabular}{|r|c|c|c|c|c|c|c|c|c|c|c|c|}
\cline { 2 - 14 } \multicolumn{1}{c|}{} & \multicolumn{4}{c|}{ Small } & \multicolumn{4}{c|}{ Medium } & \multicolumn{4}{c|}{ Large } \\
\cline { 2 - 13 } & Mean & $\begin{array}{c}\text { St } \\
\text { Dev }\end{array}$ & $\begin{array}{c}\text { Skew- } \\
\text { ness }\end{array}$ & $\begin{array}{c}\text { Kurtos } \\
\text { is }\end{array}$ & Mean & $\begin{array}{c}\text { St } \\
\text { Dev }\end{array}$ & $\begin{array}{c}\text { Skew- } \\
\text { ness }\end{array}$ & $\begin{array}{c}\text { Kurtos } \\
\text { is }\end{array}$ & Mean & $\begin{array}{c}\text { St } \\
\text { Dev }\end{array}$ & $\begin{array}{c}\text { Skew- } \\
\text { ness }\end{array}$ & $\begin{array}{c}\text { Kurtos } \\
\text { is }\end{array}$ \\
\hline K-Creation & 4.07 & 0.88 & 0.58 & 0.91 & 3.95 & 0.90 & -0.42 & 0.43 & 4.07 & 0.95 & -1.35 & 2.30 \\
\hline K-Retention & 3.88 & 1.46 & -0.32 & -0.81 & 3.96 & 1.27 & -0.43 & -0.10 & 4.19 & 1.25 & -0.50 & 0.02 \\
\hline K-Transfer & 3.67 & 1.60 & -0.20 & -1.02 & 3.88 & 1.68 & -0.25 & -0.88 & 4.03 & 1.65 & -0.36 & -0.80 \\
\hline K-Application & 4.00 & 1.70 & -0.19 & -0.97 & 3.97 & 1.47 & -0.36 & -0.44 & 4.06 & 1.60 & -0.45 & -0.44 \\
\hline
\end{tabular}

Table 4: KM-competence descriptive statistics

Table 5 reports the results of the paired independent samplet-tests for the three organizational sizes (significant at the 0.05 level). 


\begin{tabular}{|c|c|c|c|c|}
\hline & \multirow{2}{*}{$\begin{array}{c}\text { Implementation } \\
\text { K-Creation } \\
\end{array}$} & \multicolumn{3}{|c|}{ Post-Implementation } \\
\hline & & K-Retention & K-Transfer & K-Application \\
\hline & Sig / df / t-value* & $\begin{array}{l}\text { Sig/ df / t- } \\
\text { value* }\end{array}$ & $\begin{array}{l}\text { Sig/ } / \mathrm{df} / \mathrm{t}- \\
\text { value* }\end{array}$ & $\begin{array}{l}\text { Sig/ df / t- } \\
\text { value* }\end{array}$ \\
\hline Small & \multirow{2}{*}{$0.40 / 242 / .84$} & \multirow{2}{*}{$0.69 / 242 /-.40$} & \multirow{2}{*}{$0.42 / 242 /-.81$} & \multirow{2}{*}{$0.91 / 242 / .10$} \\
\hline Medium & & & & \\
\hline Small & \multirow{2}{*}{$0.98 / 112 / 0.27$} & \multirow{2}{*}{$0.01 / 112 /-2.44$} & \multirow{2}{*}{$0.01 / 112 /-1.78$} & \multirow{2}{*}{$0.85 / 112 /-.19$} \\
\hline Large & & & & \\
\hline Large & \multirow{2}{*}{$0.37 / 260 /-.89$} & \multirow{2}{*}{$0.00 / 142 /-3.33$} & \multirow{2}{*}{$0.00 / 136 /-2.39$} & \multirow{2}{*}{$.688 / 260 /-.402$} \\
\hline Medium & & & & \\
\hline
\end{tabular}

Table 5: Results of the independent sample t-test of KM-competence (*Significant at 0.005)

Following observations are made through table 5.

- $\quad$ The independent sample t-tests did not demonstrate significant differences for any pairs of firm sizes in relation to knowledge creation.

- $\quad$ Significant differences were observed between large organizations and SMEs for knowledge transfer and knowledge retention dimensions. However, no differences were observed between Small and Medium organizations for knowledge retention and knowledge transfer.

\subsection{Implications of the Organization-wide ES initiative}

We make several observations related to organization-wide ES initiatives, based on our case study, as reflected on the findings reported in Tables 1-5. Our observations are summarized in Figure 3. In Figure 3, panel A depicts changes to the ES-success dimensions for the three firm sizes across the ES lifecycle, while panel B represents the same timeline for KM-competence phases. The x-axis of panels A and B denote the key phases of the ES lifecycle, employing the three-phased ES lifecycle of Markus et al. (2003): implementation, stabilization, and shakedown. The $\mathrm{x}$-axis of panel A commences with the go-live date, given that the data collected on ES-success were made on the operational Enterprise System; while the x-axis of panel B commences with the implementation phase. Herein, knowledge creation competency involves generating knowledge with regards to business processes, organization, and software by the client, consultant, and vendor during the implementation phase, prior to the system going live.

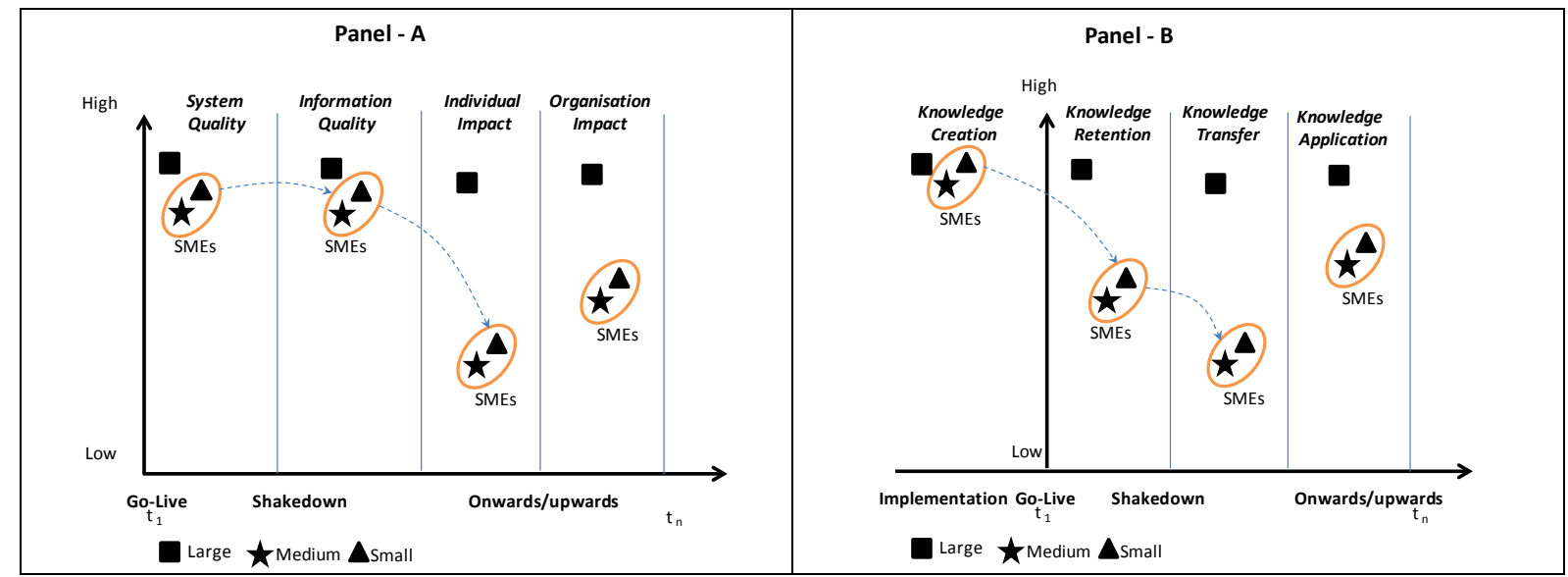

Figure 3: Implications of an organization-wide ES initiative 
For both ES-success and KM-competence, measurement constructs are positioned on the most relevant lifecycle phases, based on prior literature. Based upon the theoretical foundations of the IS Success Model of DeLone and McLean (1992), System Quality and Information Quality lead to Individual and Organizational Impacts. Additional recent research (Seddon, Calvert, \& Yang, 2010; Wang \& Sedera, 2011) suggests that organizations are more likely to observe System Quality and Information Quality during the shakedown phase of the lifecycle (and that they are less likely to see full impacts to individuals and organization) and Impacts during the follow-on onwards/ upwards phase. For KM-competence, created knowledge during the implementation phase will be retained and transferred at the shakedown phase. Though employees apply knowledge in both the shakedown and onwards/upwards phases of the lifecycle, knowledge application is more intense in the onwards/ upwards phase.

Using Figure 3, panel A, we make the following observations on organization-wide ES initiatives for ES-success.

- $\quad$ All organizations, regardless of their sizes, have attained similar levels of System and Information Quality. Though there may be continuous minor improvements to the system, the features and functions of an Enterprise System largely remains stable after the shakedown phase. Similarly, Information Quality also peaks at the end of the shakedown phase. Panel A demonstrates that System and Information Quality of all organizations remain similar. This, together with evidence that knowledge creation (in panel B) also remains similar across the three firm sizes perhaps alludes to the effectiveness of global templates. Global templates, executed through the Treasury Department provided similar levels of funds, expertise and in general all resources necessary for the ES initiative. Furthermore, the global templates monitored the delivery of the required functionality of the system and made provisions for helpdesk support and technical handovers during the shakedown phase.

- Despite achieving similar levels of success on System and Information Quality and gaining competencies in knowledge creation, SMEs could not capitalize on their initial levels of success. Figure 3 panel A shows that both Individual and Organization Impact of SMEs drop substantially in the onwards/ upwards phase. We attribute this to the lack of lifecycle wide resource availability in SMEs. Past ES studies suggest that, despite successful ES implementations, organizations must make continuous and substantial investment to gain sustained positive impacts on the relevant individuals and organization units through (i) change management, (ii) appropriate use, (iii) knowledge management, (iv) appropriate training, and (v) empowering users to ensure high levels of positive impact organization (Momoh, Roy, \& Shehab, 2010; Seddon et al., 2010; Strong \& Volkoff, 2010). Our results also provide a justifiable rationale for the smaller organizational agencies that changed their ES from SAP to the smaller, FinanceOne, during the shakedown phase, citing resource constraints.

We make the following observations, using the findings reported in Figure 3, panel $\mathrm{B}$, that focuses on KM-competence.

- $\quad$ Similar to our observations on System and Information Qualities, similar levels of knowledge creation competency gained during system implementation highlight the effectiveness of global templates. The standardized structure of governance employed through the global templates provided a highly structured approach through which the interactions of both consultants and vendors (i.e., the main knowledge sources of ES implementations) with the client organizations were managed carefully.

- $\quad$ Despite gaining similar levels of KM-competence through knowledge creation, SMEs fail to exploit on knowledge transfer and knowledge retention competencies. Most SMEs do not have the budgeting provisions to compete with well-resourced large organizations (both public and private sector). Gable et al. (1998) observed both "staff poaching" and "knowledge drain," especially in SMEs, due to the skills shortage in Enterprise Systems during the latter half of the 1990s, thereby highlighting the 
importance of organizational knowledge retention strategies for ES-success throughout the entire lifecycle.

Our findings suggest that SMEs find it difficult to generate value from ES beyond what they receive during the implementation phase. Furthermore, they fail to develop on-going ESrelated knowledge management competencies necessary for wellbeing throughout the lifecycle. Though further research is needed to conclusively identify how global templates help SMEs in managing ES initiatives, our findings suggest that global templates have been effective in delivering similar level of success and competencies. However, our findings also suggest that the coverage of global templates should extend beyond its focus on the implementation phase and should include strategies and resources for the entire lifecycle.

\subsection{A Consolidated Path Model}

A consolidated path model is designed and tested to understand the implications for the third hypothesis. Herein, we follow guidelines of Plouffe et al. (2001), and conduct a multi-group PLS analysis (Wold, 1989) using SmartPLS software (Ringle, 2005) to understand the influence of firm size on the causal relationship between KM-competence and ES-success. Figure 4 demonstrates the results of the path model analysis.
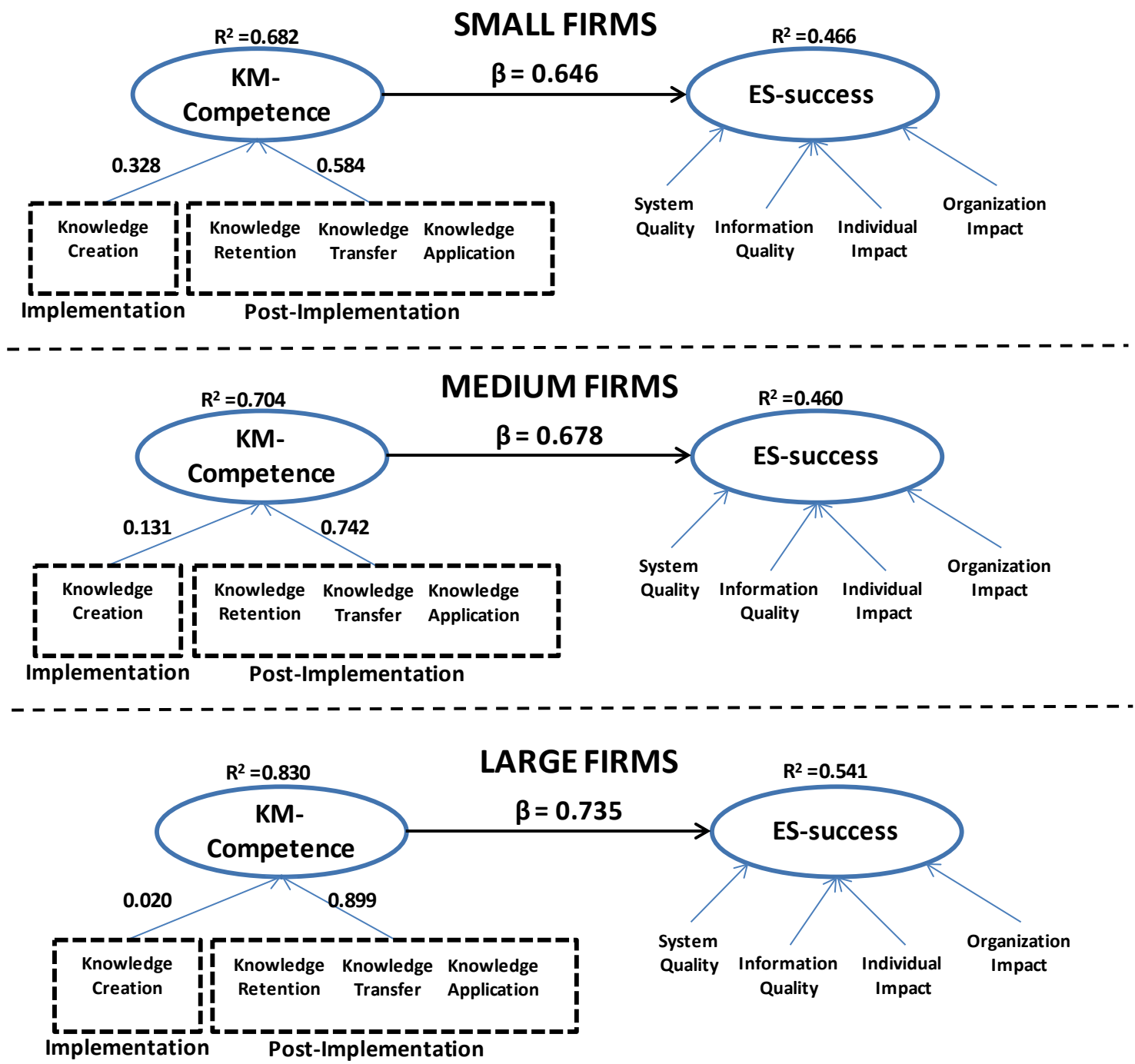

Figure 4: Path model of knowledge management for ES-success

Several observations can be made from the path model results shown in Figure 4: 
- $\quad$ All three models, regardless of the firm size, demonstrate large, statistically significant path coefficients between KM-competence and ES-success, with approximately $50 \%$ of the variance of ES-success, is explained by KM-competence ( $r$-square values for ESsuccess range between 0.46 and 0.54 ). Findings further strengthen KM-competence as a critical antecedent of ES-success.

- We notice that R2 values of both constructs - ES-success and KM-competence decline with the descending firm size, with large organizations reporting the highest values and smaller organizations reporting the lowest values.

- $\quad$ Similarly, path coefficient between KM-competence and ES-success also declined with the descending order of firm size (coefficient for small $=0.646$; medium $=0.678$; large $=0.735$ ).

- Investigating the extent to which KM-competence is determined by its individual constructs (i.e. creation, retention, transfer, and application), we observe the loadings of each construct across the three firm sizes. Here, we observe that small firms have the highest loading for KM-competence gained through knowledge creation, while the loadings of knowledge creation on KM-competence decline with the increasing firm size.

- However, large organizations demonstrate the highest loadings for KM-competence gained through post-implementation knowledge management activities (retention, transfer, and application), while the loadings of post-implementation knowledge management competence is lowest in small organizations.

Consistent with the observations of Sedera and Gable (2010), our multi-group analysis demonstrates the positive, significant relationship between KM-competence and ES-success. The path coefficients and R-square values suggest that the data from large organizations fit better with our research model than with smaller organizations. The results also highlight a shift in emphasis for gaining KM-competence across the three firm sizes. For example, large organizations place a greater emphasis on post-implementation activities (retention, transfer, and application), when defining KM-competence. The results suggest that KM-competence in small organizations is still based largely on knowledge created during the implementation period.

\section{Discussion}

The goal of this study was to test statistically the implied influence of firm size on system success and knowledge-management competence in a large-scale, multidivisional Enterprise System initiative. The research insights were gained through an investigation of the first major public-sector SAP installation in the world, which integrated 27 different departments into a single SAP implementation. The study model investigated KM-competence, as defined by Sedera and Gable (2010), and ES-success using notions of the DeLone and McLean IS Success Model. The study model was then tested with a data sample of 310 respondents, providing descriptive, comparative, and multi-group analyses, yielding several observations and interpretations.

In summary, the three kinds of organizational units - small, medium, and large - did not demonstrate any statistically significant differences for knowledge creation and knowledge application constructs as the independent variables and System Quality and Information Quality as the dependent variables. We attribute these characteristics to the similarities in the implementation approach followed by the lead agency, the Treasury Department. Given that all 27 of the subsidiary organizations followed the same SAP global template, using the same corporate-wide software platform, we would have expected these similarities in the beginning of the ES lifecycle. However, we observed differences between large and smaller counterparts for Individual Impact, Organizational Impact, knowledge retention, and knowledge transfer. Despite attaining similar levels of Information and System Quality and gaining similar levels of KM-competence through knowledge creation, we found that SMEs, in comparison to larger 
organizations, failed to carry their progress attained during the implementation/ shakedown phase through to the latter onwards/ upwards phase of the ES lifecycle. Thus, our results demonstrated significant differences between large organizations and SMEs for Individual Impacts, Organization Impacts, knowledge retention, and knowledge transfer. Many factors could have contributed to the lack of progress of SMEs in the onwards/upwards phase. In general, it highlights the weaknesses in lifecycle-wide management capabilities of SMEs for large-scale business information system initiatives.

The lack of preparation and attention to ES lifecycle management in SMEs is further evidenced through the multi-group PLS analyses, where KM-competency of SMEs is primarily attributed to knowledge created during the implementation phase. In contrast, KM-competence in large organizations is viewed more through the activities conducted during the onwards/upwards phase through knowledge retention and knowledgetransfer. Post-implementation knowledge transfer and knowledge retention showed substantially lower mean scores for both small and medium organizations.

Our research findings also provide insights into the role of global implementation templates in large-scale, multidivisional ES implementations. For example, all organizations in our study managed to attain a similar level of success and competency at the go-live time. The use of global templates appeared to have helped the SMEs to devise a workable approach to software acquisition and communication strategies, to gaining a higher degree of IT sophistication, and to increasing the level of risk tolerance throughout the organizations.

Finally, our study identified a repeatable and generalizable classification scheme and heuristics to categorize firm size, based on the number of user licenses. Future research could use these heuristics in firm size studies to establish a cumulative tradition of research.

\subsection{Implications for Research}

Although studies of firm-size implications date back to the 1970s, this study is one of the few to have researched the firm-size implications in a large-scale Enterprise System initiative, focusing on ES-success and KM-competence. There are several research implications of this study.

First, answering calls by Goode and Gregor (2009) for establishing information-systemspecific classification and heuristics to determine firm size, this study established a repeatable and generalizable classification scheme for categorizing firms according to size using the number of software user licenses. This new classification method, with its corresponding cutoff values, will add uniformity to future firm-size research, where firm size can now be specified using a common, simple, yet consistent criterion. Moreover, unlike prior classifications of firm size based on revenue, number of employees, or budgets, our classification has a direct, logical, relationship with information systems. Moreover, it is expected that organizations will be less sensitive to revealing the number of user licenses, as opposed to information on IT budgets, headcounts, or other financial information. However, this new firm-size classification scheme should be tested in future studies to further establish its validity as a classification method.

Second, this study contributes to the lack of knowledge of large-scale, corporate-wide Enterprise System initiatives. To the best of our knowledge, we are unaware of any such studies that investigated a corporate-wide ES initiative that gathered data from all of its organizational entities. In our study, we analysed the management of such corporate-wide initiatives through the use of the "panoptic gaze." Through a detailed study context, our study highlights how such management practices are accomplished through a lead department governing the ES implementation process from the initial User Requirements Analysis (URA) to the go-live date.

Despite some studies suggesting that the use of global templates may be harmful to smaller subsidiaries (Avison \&Malaurent, 2007), our study provided counter evidence, demonstrating that all organizations, regardless of the size, could attain similar levels of success and competence to the go-live date. 
Finally, our model test results re-validate the dimensions of KM-competence (Gable and Sedera 2010) and the IS-Impact Measurement Model of Gable, Sedera, and Chan (2008). Furthermore, the results re-confirm the statistically significant impact of KM-competence as an antecedent of ES-success.

\subsection{Implications for Practice}

At a time when Enterprise-System vendors are aggressively moving towards scaled-down Enterprise Systems for SMEs (e.g., SAP's ByDesign, Microsoft's NAV), our study results provide some cautionary insights into the long-term viability of ES in SMEs. Despite attaining similar levels of System and Information Success, SMEs failed to reap similar levels of benefits in Individual and Organizational Impacts. Our results highlight the need for SMEs to develop an ES lifecycle management plan, wherein adequate resources are dedicated, not only to the initial implementation process, but for the entire lifecycle.

Our results provide some degree of comfort for practitioners who undertake similar corporatewide ES initiatives and who use management control through global templates. Our study highlighted how a lead agency, in this case the state Treasury Department, used global templates for the entire ES lifecycle, providing tight management control for all parts of the organization at every stage prior to implementation, thus achieving reasonable measures of success and KM-competence. However, it highlights the weaknesses in the current approach, where the Treasury Department support and control seem to have diminished immediately following the go-live date. Unlike large organizations where resources and motivations are adequate, SMEs require continuous support and guidance for their ES initiatives to be successful. Our study highlights the importance incorporating a lifecycle-long strategy for the use of global templates, including attention to the retention of knowledge within the organization and transferring it to the required staff through appropriate channels. This view has been echoed in Chang et al. (2000), who argued that organizations require a lifecycle-long knowledge-sourcing strategy in Enterprise System projects. Low mean scores of SMEs in relation to the knowledge retention and transfer dimensions provide clear evidence of a "knowledge drain." Gable, Scott, and Davenport (1998) also recognized this occurrence of "staff poaching" and "knowledge drain" due to ES skill shortages in the late 1990s, and these problems remain.

Having explained almost half of the variance in ES-success across the 27 organizations studied, KM-competence was identified as possibly the most important antecedent of success. Given that many ES installations around the world struggle to deliver expected benefits, we recommend a stronger emphasis be placed on related-knowledge management. The study's results reinforce the early calls of researchers (Davenport, De Long, \& Beers, 1998; Newell, Huang, \&Tansley, 2006) to make an end-to-end lifecycle ES knowledge-management strategy available to those organizations involved in undertaking the implementation of an ES.

\subsection{Limitations and Future Research}

This study has several limitations. First, the data were gathered only from a public-sector organization, using a single SAP application, suggesting that further testing in other industry sectors, with other Enterprise Systems, would contribute to the generalizability of the findings. The firm-size classification scheme also has its limitations. First, the sample only included organizations using SAP applications. Thus, the classification method should be tested with other types of information systems for its generalizability. Also, the size cut-offs were determined in an inductive manner. Further research should be conducted to generalize these firm-size dimensions as well. Furthermore, the study's results should be triangulated using alternative firm-size classifications (e.g., financial indicators). This study observed the outcomes employing global templates in a corporate-wide ES initiative. However, the scope of the current study did not allow us to make deep observations on the role of global templates in corporate-wide ES initiatives. This too is an important research direction. 


\section{References}

Alavi, M., \& Leidner, D. E. (2001). Review: Knowledge Management And Knowledge Management Systems: Conceptual Foundations And Research Issues. MIS Quarterly, 25(1): 107-136.

Argote, L., McEvily, B., \& Reagans, R. (2003). Managing Knowledge In Organizations: An Integrative Framework And Review Of Emerging Themes. Management Science, 49(4): 571-582.

Avison, D., \& Malaurent, J. (2007). Enterprise Resource Planning Software in China: A Disaster Story. Intercultural Management Quaterly, 8(2).

Bacher, J ., Wenzig, K., \&Vogler, M. (2010). SPSS Two-Cluster - A First Evaluation available at http:/ / www.statisticalinnovations.com/ products/ twostep.pdf

Bernroider, E. W. N., \& Koch, S. (2000). Differences in Characteristics of the ERP System Selection Process between Small or Medium and Large Organizations Sixth Americas Conference on Information Systems (AMCIS 2000): 1022-1028. Long Beach California: AIS.

Bilili, S., \& Raymond, L. (1993). Information technology: threats and opportunities for small and medium-sized enterprises. International J ournal of Information Management, 13(6): 439-448.

Cenfetelli, R. T., \& Bassellier, G. (2009). Interpretation of Formative Measurement in Information Systems Research. MIS Quarterly, 33(4): 689-707.

Chang, S.-I., Gable, G., Smythe, E., \& Timbrell, G. (2000). Major Issues With Enterprise Systems: A Case Study And Survey Of Five Government Agencies. Paper presented at the Proceedings of the 21 $1^{\text {st }}$ International Conference on Information Systems Brisbane, Australia.

Cheney, P. H. (1983). Getting The Most Out Of Your First Computer System. American J ournal of Small Business, 7(4): 476-485.

Clemmons, S., \& Simon, S. J . (2001). Control and Coordination in Global ERP Configuration. Business Process Management J ournal 7(3): 205-215.

Cooley, P. L., Walz, D. T., \&Walz, D. B. (1987). A Research Agenda For Computers And Small Business. American J ournal of Small Business, 11(3): 31-42.

Davenport, T. H., De Long, D. W., \& Beers, M. C. (1998). Successful knowledge management projects. , Sloan Management Review, 39(2): 43-57.

DeLone, W. H. (1981). Firm Size And The Characteristics Of Computer Use. MIS Quarterly, 5(4): 65-77.

DeLone, W. H., \& McLean, E. R. (1992). Information Systems Success: The Quest For The Dependent Variable. Information Systems Research, 3(1): 60-95.

Diamantopoulos, A. (2009). Reflective and formative metrics of relationship value: Response to Baxter's commentary essay. Journal of Business Research doi:10.1016/j.jbusres.2009.03.001.

Diamantopoulos, A., \& Winklhofer, H. M. (2001). Index Construction with Formative Indicators: An Alternative to Scale Development. J ournal of Marketing Research, 38(2): 269-273.

Doukidis, G. I., Lybereas, P., \& Galliers, R. D. (1996). Information systems planning in small businesses: a stage of growth analysis. J ournal of Systems and Software, 33 (2): 189201.

Ein-Dor, P., \& Segev, E. (1978). Organizational Context And The Success Of Management Information Systems. Management Science, 24(10): 1064-1077. 
Elmes, M. B., Strong, D. M., \& Volkoff, O. (2005). Panoptic empowerment and reflective conformity in enterprise systems-enabled organizations. Information and Organization, 15(1): 1-37.

Esteves, J., \& Pastor, J. (2005). A critical success factor's relevance model for SAP implementation projects. In M. Khosrow-Pour (Ed.), Managing Business with SAP: 240-262. Hershey, PA: Idea Group Publishing.

Farhoomand, F., \& Hrycyk, G. P. (1985). The Feasibility Of Computers In The Small Business Environment. American J ournal of Small Business, 9(4): 15-22.

Gable, G., Sedera, D., \&Chan, T. (2008). Re-conceptualizing Information System Success: The IS-Impact Measurement Model. J ournal of Association for Information Systems, 9(7): 377-408.

Gable, G. G., Heever, R. v. D., Erlank, S., \& Scott, J . (1997). Large Packaged Software: The Need For Research. Paper presented at the Proceedings of the $3^{\text {rd }}$ Pacific Asia Conference on Information Systems Brisbane, Australia.

Gable, G. G., Scott, J., \& Davenport, T. (1998). Cooperative ERP Life Cycle Knowledge Management. Paper presented at the Proceedings of the $9^{\text {th }}$ Australasian Conference on Information Systems Sydney, New South Wales, Australia.

Gable, G. G., \& Stewart, G. (1999). SAP R/3 Implementation Issues For Small To Medium Enterprises. Paper presented at the Proceedings of the $5^{\text {th }}$ Americas Conference on Information Systems, Milwaukee, Wisconsin.

Goode, S., \& Gregor, S. (2009). Rethinking Organisational Size: Meaning, Measurement and Redevelopment. European J ournal of Information Systems, 18(1): 14-25.

Hage, J . (1980). Theories of Organization. New York: Wiley Publishers.

Hauser, R. M., \& Goldberger, A. S. (1971). The treatment of unobservable variables in path analysis. In H. L. Costner (Ed.), Sociological Methodology: 81-117. San Francisco: J ossey-Bass.

Jarvis, C. B., MacKenzie, S. B., \& Podsakoff, P. A. (2003). A critical review of construct indicators and measurement model misspecification in marketing and consumer research. J ournal of Consumer Research, 30(2): 199-216.

J oreskog, K. G., \&Goldberger, A. S. (1975). Estimation of a Model with Multiple Indicators and Multiple Causes of a Single Latent Variable Journal of the American Statistical Association, 70, (351): 631-639.

Kleinbaum, D. G., Kupper, L. L., Muller, K. E., \& Nizam, A. (1998). Applied Regression Analysis and Other Multivariate Methods. Belmont, California: Duxbury Press.

Laukkanen, S., Sarpola, S., \& Hallikainen, P. (2007). Enterprise size matters: objectives and constraints of ERP adoption. J ournal of Enterprise Information Management, 20(3): 319-334.

Levy, M., \& Powell, P. (1998). SME flexibility and the role of information systems. Small Business Economics, 11(2): 183-196.

Mabert, V. A., Soni, A., \&Venkataramanan, M. A. (2003). The impact of organizationsize onen terprise resource planning (ERP) implementations in the US manufacturing sector. Omega, 31: 235-246.

Madapusi, A., \& D'Souza, D. (2005). Aligning ERP Systems with International Strategies. Information Systems Management, 22(1): 7-17

Madapusi, A., \& D'Souza, D. (2007). A Framework for Aligning the ERP System with the International Strategy of Small Firms. Paper presented at the Academy of Management Conference, Philadelphia. 
Markus, L. (2001). Toward A Theory Of Knowledge Reuse: Types Of Knowledge Reuse Situations And Factors In Reuse Success. J ournal of Management Information Systems, 18(1): 57-93.

Markus, L., Axline, S., Petrie, D., \&Tanis, C. (2003). Learning from Adopters' Experiences with ERP: Problems Encountered and Success Achieved. In G. Shanks, P. Seddon, \& L. Willcocks (Eds.), Second-Wave Enterprise Resource Planning Systems. Cambridge, UK: Cambridge University Press, .

Mintzberg, H. (1979). The Structuring of Organizations. Englewood Cliffs, New Jersey: Prentice-Hall.

Mitev, N. N., \& Marsh, A. E. (1998). Small businesses and information technology: risk, planning and change. J ournal of Small Business and Enterprise Development, 5(3): 228-245.

Momoh, A., Roy, R., \& Shehab, E. (2010). Challenges in Enterprise Resource Planning Implementation: State-of-the-Art. Business Process Management J ournal, 16(4): 537565.

Montazemi, A. R. (1988). Factors Affecting Information Satisfaction In The Context Of The Small Business Environment. MIS Quarterly, 12(2): 238-256.

Newell, S., Huang, J ., \& Tansley, C. (2006). ERP Implementation: A Knowledge Integration Challenge for the Project Team. Knowledge and Process Management 13(4): 227-238.

Nord, W. R., \& Tucker, S. (1987). Implementing Routine and Radical Innovations. San Francisco: New Lexington Press.

Pan, G., \& Chen, A. J . W. (2005). Enterprise Systems Planning Projects in China. In S. L. Pan (Ed.), Managing Emerging Technologies and Organizational Transformation in Asia, Vol. 2. Singapore: World Scientific Publishing Co. Pte. Ltd.

Pan, S. L., Newell, S., Huang, J ., \&Galliers, R. D. (2007). Overcoming Knowledge Management Challenges During ERP Implementation: The Need to Integrate and Share Different Types of Knowledge. J ournal of the American Society for Information Science and Technology, 58(3): 404-419.

Petter, S., Straub, D., \& Rai, A. (2007). Specifying Formative Constructs in Information systems research. MIS Quarterly, 31(4): 623-656.

Plouffe, C. R., Vandenbosch, M., \&Hulland, J . (2001). Intermediating technologies and multigroup adoption: A comparison of consumer and merchant adoption intentions toward a new electronic payment system. The J ournal of Product Innovation Management, 18: 65-81.

Proudlock, M. J., Phelps, B., \& Gamble, P. (1999). IT adoption strategies: best practice guidelines for professional SMEs. Journal of Small Business and Enterprise Development, 6(4): 240-252.

Punj, G., \&Stewart, D. W. (1983). Clustering in Marketing Research: A Reviewand Suggestions for Application. J ournal of Marketing Research, 10(May): 134-148.

Raymond, L. (1985). Organizational Characteristics And MIS Success In The Context Of Small Business. MIS Quarterly, 9(1): 37-52.

Ringle, C., Wende, S., and Will, A. (2005). SmartPLS 2.0 (beta): University of Hamburg. Retrieved March 28, 2007 from http:/ / www.smartpls.de.

Salim, S.A., Sedera, D., Sawang, S., Alarifi, A., Atapattu M., (2015) Moving from Evaluation to Trial: How do SMEs Start Adopting Cloud ERP? Australasian J ournal of Information Systems, 19 doi: http:/ / dx.doi.org/ 10.3127/ ajis.v19i0.1030 
Schultz, R. L., \&Slevin, D. P. (1975). Implementation and organisational validity: an empirical investigation. In R. L. Shultz, \& D. P. Slevin (Eds.), Implementing operational research / management science: 153-182. New York: Elsevier, North-Holland.

Seddon, P. B., Calvert, C., \& Yang, S. (2010). A Multi-Project Model of Key Factors Affecting Organizational Benefits From Enterprise Systems. MIS Quarterly, 34(2): 305-A311.

Sedera, D., \& Gable, G. (2010). Knowledge Management Competence for Enterprise System Success. J ournal of Strategic Information Systems, 19(1): 296-306.

Sedera, D., Lokuge, S. Grover, V., Sarker, S., Sarker S., Innovating with Enterprise Systems and Digital Platforms: A Contingent Resource-Based Theory View, Information \& Management, 53(3), 297-408

Semple, J. (1993). Bentham's Prison: a Study of the Panopticon Penitentiary. Oxford: Clarendon Press.

Sia, S. K., M. Tang, Soh, C., \&Boh, W. F. (2002). Enterprise resource planning (ERP) systems as a technology of power: empowerment or panoptic control? SIGMIS Database, 33(1): 23-37.

Sistach, F., \& Pastor, J . A. (Eds.). (2000). Methodological acquisition of ERP solutions with SHERPA: tenHagenStam.

Sistach, F., Pastor, J . A., \& Fernandez, L. F. (1999). Towards the methodological acquisition of ERP solutions for SMEs. Paper presented at the EMRPS'99- Enterprise Management and Resource Planning Systems proceedings

Soh, C., Sia, S. K., \&Tay-Yap, J . (2000). Cultural Fits And Misfits: Is ERP A Universal Solution? Communications of the ACM, 43(4): 47-51.

Soh, C. P. P., Yap, C. S., \& Raman, K. S. (1992). Impact of consultants on computerisation success in small businesses. Information and Management, 22: 309-319.

Strong, D. M., \& Volkoff, O. (2010). Understanding Organization--Enterprise System Fit: A Path To Theorizing The Information Technology Artifact. MIS Quarterly, 34(4): 731756.

Sverlinger, P. O. M. (2000). Managing Knowledge in Professional Service Organisations: Technical Consultants Serving the Construction Industry - PhD Thesis Chalmers University of Technology Goteborg

Turner, J . S. (1992). Personal DSS success in small business. Information and Management, 22: 301-308.

Wang, R., \& Hamerman, P. D. (2008). Topic Overview: ERP Applications 2008: 19: Forrester Research, Inc.

Wang, W., \& Sedera, D. (2011). A Benefits Expectation Management Framework for Supply Chain Management Systems. Paper presented at the International Conference on Information Systems, Shanghai - China.

Whisler, T. (1970). The Impact Of Computers On Organizations. New York, NY: Praeger Publishers.

Wold, H. (1989). Introduction to the second generation of multivariate analysis. In $\mathrm{H}$. Wold (Ed.), Theoretical Empiricism: vii-xl. New York: Paragon House.

Zuboff, S. (1988). In theAge of the Smart Machine: TheFuture of Work and Power. NewYork: Basic Books. 


\section{Appendix A - Impact of Firm Size on ES-Lifecycle}

\section{Firm Size Implications: System Selection and Implementation}

Whisler (1970), Schultz and Slevin (1975), and Ein-Dor and Segev (1978) were among the first IS researchers to suggest the importance of considering firm size in IS implementations. In their early work, Ein-Dor and Segev (1978) proposed a framework for IS implementations, where they recognised the influence of firm size on resource availability, the requirements necessary for integration of professional units within an organization, the degree of formalisation of organizational systems, and the lead times for planning and implementation. Similarly, they demonstrated that IS projects are less likely to succeed in smaller organizations compared to their larger counterparts. Bilili and Raymond (1993) described the SME decisionmaking process in system selection as reactive, informal, and intuitive. Cheney (1983) investigated various factors affecting small businesses in IS implementations and found that they are prone to software and hardware problems during implementation.

Investigating IS acquisition in medium and large organizations, Turner (1992) recommended that SMEs develop applications in-house, rather than opting for packaged applications. Similarly, Raymond (1985) found that SMEs were better able to develop, implement, and administer their own applications in-house, compared to their larger counterparts. He also found that medium-sized organizations could maintain information systems with minimal financial, technical, and personnel requirements. Moreover, historical studies suggest that smaller organizations can adapt to a higher degree of technological innovation than larger organizations (Mintzberg, 1979; Nord \& Tucker, 1987). Nord and Tucker (1987) argued that, although large organizations are more complex, they could easily adopt new technological innovations, using their resources and facilities such as financial strength, communication skills, research capabilities, and product development experience. They also found that the greater resources which exist in large organizations provide a certain tolerance for potential losses due to unsuccessful implementations (Nord and Tucker 1987).

Given the natural association of ES with large organizations, only a handful of studies have investigated the prospects of ES in SMEs (Esteves \& Pastor, 2005). For example, Gable and Stewart (1999) analysed SME Enterprise System implementations and found resource deficiency and lack of expertise as major barriers to ES adoption. On the other hand, Sistach et al. (1999) and Sistach and Pastor (2000) argued that smaller firm size could be beneficial to SMEs in ES implementations. Bernroider and Koch (2000) detailed the results from an empirical study concerning differences in characteristics of the ES selection process among small, medium, and large organizations. They found decision-making in the SME ES selection process to be reactive, informal, and intuitive, re-confirming prior observations made in legacy applications (Bilili \& Raymond, 1993; Cheney, 1983).

\section{Firm Size Implications: Post-Implementation Management}

Researchers assert that SMEs tend to have an opportunistic, day-to-day focus in relation to IS benefits and seldom consider long-term benefits of a system (Doukidis, Lybereas, \& Galliers, 1996; Proudlock, Phelps, \& Gamble, 1999). Whisler (1970) investigated 19 insurance companies and concluded that firm size was directly related to IS performance, with SMEs receiving substantially fewer returns compared to their larger counterparts. Montazemi (1988), investigating the aforementioned preposition, confirms the impact of organizational size on end-user satisfaction, claiming that users in large organizations are more satisfied with the IS than users in smaller organizations.

DeLone (1981) studied the relationship between the size of manufacturing firms and IS usage. He concluded that firm size is: (1) directly related to the age of the firm's computer operations, (2) inversely related to the amount of external support being used, and (3) directly related to the financial resources made available to the initiative. It is also noted that resource constraints lead to SMEs following an incremental approach to IT investments, which, in turn, may result in isolated and incompatible systems, as well as limited flexibility (Levy \&Powell, 1998). 
A study by Cooley et al. (1987) of mid-sized organizations identified user-friendly interfaces as the key factor of end-users' satisfaction, while lower implementation costs were the most important for the management of SMEs. Some scholars argue that smaller organizations have greater flexibility, a higher ability to adapt and improve, and find it easier to accept and implement change initiatives (Hage, 1980).

Lifecycle-long dedication to KM-competence of SMEs too has been discussed in prior academic studies, with most research suggesting a lack of resident knowledge and expertise on systems in SMEs (Bilili \& Raymond, 1993; Levy \& Powell, 1998; Mitev \& Marsh, 1998). Turner (1992) suggested that SMEs require assistance from external sources in creating knowledge in IS adoption and management. Similarly, Soh et al. (1992) and Gable et al. (1998) allude to the importance of seeking expert assistance from consultants when undertaking computerization in small businesses. They report better system usage in small businesses when consultants were employed. Addressing the technical know-how within organizations, Farhoomand and Hrycyk (1985) reported that small- to medium-sized companies lack adequate in-house technical staff for managing IS system lifecycle issues. SMEs, in general, are considered low in KM-competence. Research suggests that the resource constraints of SMEs hinder their ability to maintain knowledge within organizations and stay up-to-date with technology innovations, and that they are ill-prepared for managing long-term IT investments (Laukkanen et al., 2007; Levy \& Powell, 1998). 


\begin{tabular}{|c|c|c|c|c|}
\hline \multirow[b]{2}{*}{ Characteristics } & \multicolumn{3}{|c|}{ Firm Sizes } & \multirow[b]{2}{*}{ Reference } \\
\hline & Large & Medium & Small & \\
\hline $\begin{array}{l}\text { Acquisition } \\
\text { Procedure }\end{array}$ & Rational, futuristic & Procedural & Ad-hoc, reactive & $\begin{array}{l}\text { Bilili and Raymond } \\
\text { (1993); Cheney (1983) }\end{array}$ \\
\hline Change Initiatives & $\begin{array}{l}\text { Much effort, } \\
\text { externally managed }\end{array}$ & $\begin{array}{l}\text { Internally managed } \\
\text { with external } \\
\text { templates }\end{array}$ & $\begin{array}{l}\text { Internally managed, } \\
\text { relatively easy } \\
\text { changes }\end{array}$ & Raj and Bajwa (1997) \\
\hline $\begin{array}{l}\text { Communication } \\
\text { and Coordination }\end{array}$ & $\begin{array}{l}\text { Much effort, greater } \\
\text { need, highly } \\
\text { structured }\end{array}$ & $\begin{array}{l}\text { Less structured, high } \\
\text { need }\end{array}$ & fairly unstructured & $\begin{array}{l}\text { Leifer (1988); Rai and } \\
\text { Bajwa (1997) }\end{array}$ \\
\hline Complexity & $\begin{array}{l}\text { Very complex with } \\
\text { many extraneous } \\
\text { variables }\end{array}$ & Less complex & Simple, rule-based & $\begin{array}{l}\text { Hall et al. (1967); } \\
\text { Gerhart et al. (1990) }\end{array}$ \\
\hline $\begin{array}{l}\text { Degree of } \\
\text { Structure }\end{array}$ & Structured & Rhythmic, procedural & $\begin{array}{l}\text { Unstructured, } \\
\text { irregular }\end{array}$ & $\begin{array}{l}\text { Hart et al. (1994); } \\
\text { Brouthers et al. } \\
\text { (2000) }\end{array}$ \\
\hline Economies of scale & Greater & Some what & Low & Orlitzky (2001) \\
\hline Flexibility & Rigid & Firm & Flexible & $\begin{array}{l}\text { Fiegenbaum et al. } \\
\text { (1991); Hitt et al. } \\
\text { (1997); Kalantaridis } \\
\text { (2004) }\end{array}$ \\
\hline IS Evaluations & Critical \& futuristic & Short Term & $\begin{array}{l}\text { Optimistic \& day-to- } \\
\text { day focus }\end{array}$ & $\begin{array}{l}\text { Doukidis et al. (1996); } \\
\text { Proudlock et al. } \\
\text { (1999); Whisler } \\
\text { (1970); Montazemi } \\
\text { (1988) }\end{array}$ \\
\hline IS Sophistication & High & Medium & Low & $\begin{array}{l}\text { Yao et al. (2002); } \\
\text { Goss et al. (1994) }\end{array}$ \\
\hline IT innovation & Low & Medium & High & $\begin{array}{l}\text { Turner (1992); } \\
\text { Raymond (1985); } \\
\text { Harrison (1997); } \\
\text { Stock et al. (2002) }\end{array}$ \\
\hline IT investment & High \& continuous & Periodic & Incremental & Levy et al. (1998) \\
\hline $\begin{array}{l}\text { Knowledge / } \\
\text { Expertise }\end{array}$ & High & Medium & Low & $\begin{array}{l}\text { Nord and Tucker } \\
\text { (1987); DeLone } \\
\text { (1981); Bilili et al. } \\
\text { (1993); Levy et al. } \\
\text { (1998); Mitev et al. } \\
\text { (1998); Russell et al. } \\
\text { (1998) }\end{array}$ \\
\hline Need for Control & High & Moderate & Low & $\begin{array}{l}\text { Blau (1970); Rai et al. } \\
\text { (1997) }\end{array}$ \\
\hline $\begin{array}{l}\text { Resource } \\
\text { Availability }\end{array}$ & Adequate & Restrained & Limited & $\begin{array}{l}\text { Ein-Dor and Segev } \\
\text { (1978); Lang et al. } \\
\text { (1997); Yeo et al. } \\
\text { (2002); DeLone et al. } \\
\text { (1981); Cooley et al. } \\
\text { (1987); Laukkanen et } \\
\text { al. (2007) }\end{array}$ \\
\hline Risk Aversion & Less & Moderate & More & Arrow (1962) \\
\hline Risk Tolerance & Greater scale & Moderate & Minimal & Hitt et al. (1997) \\
\hline Slack Resources & More & Adequate & Less & $\begin{array}{l}\text { Pearce et al. (1992); } \\
\text { Rogers (1995); Bowen } \\
\text { (2002) }\end{array}$ \\
\hline $\begin{array}{l}\text { Tolerance of } \\
\text { Losses }\end{array}$ & High leeway & Moderate & Restrictive & $\begin{array}{l}\text { Nord and Tucker } \\
(1987)\end{array}$ \\
\hline
\end{tabular}




\section{Appendix B - The Survey Instrument}

\section{Individual-Impact}

1. I havelearnt much through the presence of (the IS).

2. (the IS) enhances my awareness and recall of job related information

3. (the IS) enhances my effectiveness in thejob

4. (the IS) increases my productivity

\section{Organizational-Impact}

5. (the IS) is cost effective

6. (the IS) has resulted in reduced staff costs

7. (the IS) has resulted in cost reductions (e.g. inventory holding costs, administration expenses)

8. (the IS) has resulted in overall productivity improvement

9. (the IS) has resulted in improved outcomes or outputs

10. (the IS) has resulted in an increased capacity to manage a growing volume of activity (e.g. transactions, population growth, etc.)

11. (the IS) has resulted in improved business processes

12. (the IS) has resulted in better positioning for e-Government/ Business.

\section{Information-Quality}

13. (the IS) provides output that seems to be exactly what is needed

14. Information needed from (the IS) is always available

15. Information from (the IS) is in a form that is readily usable

16. Information from (the IS) is easy to understand

17. Information from (the IS) appears readable, clear and well formatted

18. Information from (the IS) is concise

\section{System-Quality}

19. (the IS) is easy to use

20. (the IS) is easy to learn

21. (the IS) meets (the Unit's) requirements

22. (the IS) includes necessary features and functions

23. (the IS) always does what it should

24. The (the IS) user interface can be easily adapted to one's personal approach

25. (the IS) requires only the minimum number of fields and screens to achieve a task

26. All data within (the IS) is fully integrated and consistent

27. (the IS) can be easily modified, corrected or improved

\section{Knowledge Creation}

28. Overall, SAP knowledge possessed by the vendor (SAP Australia) has been appropriate

29. Overall, SAP knowledge possessed by the consultants has been appropriate

30. Overall, SAP knowledge possessed by the agency has been appropriate

31. Overall, knowledge of the agency, possessed by the vendor (SAP Australia) has been appropriate

32. Overall, knowledge of the agency, possessed by the consultants has been appropriate

33. Overall, the Agency knowledge of itself (e.g. Business processes, internal policies, etc.) has been appropriate

\section{Knowledge Retention}

34. Overall, SAP staff and Knowledge Retention strategies have been effective

35. The Agency has retained the knowledge necessary to adapt the SAP system when required

\section{Formal Knowledge Transfer}

36. Training in SAP has been appropriate

\section{Knowledge Application}

37. Overall, SAP knowledge has been re-used effectively and efficiently by the agency 


\section{Criterion Items}

38. Overall, the impact of SAP on me has been positive.

39. Overall, the impact of SAP on the agency has been positive.

40. Overall, the SAP System Quality is satisfactory.

41. Overall, the SAP Information Quality is satisfactory.

42. Overall, SAP system related knowledge has been managed satisfactorily

Copyright: (C) 2016 Sedera. This is an open-access article distributed under the terms of the Creative Commons Attribution-NonCommercial 3.0 Australia License, which permits noncommercial use, distribution, and reproduction in any medium, provided the original author and AJ IS are credited.

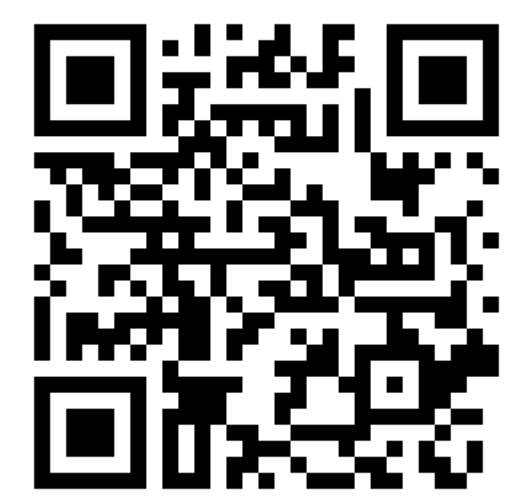

